\title{
Maria di Francia, Il purgatorio di San Patrizio
}

\section{Maria Colombo Timelli}

\section{(2) OpenEdition}

\section{Journals}

\section{Édition électronique}

URL : http://journals.openedition.org/studifrancesi/32797

DOI : 10.4000/studifrancesi.32797

ISSN : 2427-5856

Éditeur

Rosenberg \& Sellier

\section{Édition imprimée}

Date de publication : 1 décembre 2005

Pagination : 613-614

ISSN : 0039-2944

\section{Référence électronique}

Maria Colombo Timelli, « Maria di Francia, Il purgatorio di San Patrizio », Studi Francesi [En ligne], 147 (XLX | III) | 2005, mis en ligne le 30 novembre 2015, consulté le 19 avril 2021. URL : http:// journals.openedition.org/studifrancesi/32797 ; DOI : https://doi.org/10.4000/studifrancesi.32797

Ce document a été généré automatiquement le 19 avril 2021.

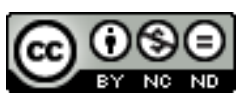

Studi Francesi è distribuita con Licenza Creative Commons Attribuzione - Non commerciale - Non opere derivate 4.0 Internazionale. 


\title{
Maria di Francia, Il purgatorio di San Patrizio
}

\author{
Maria Colombo Timelli
}

\section{RÉFÉRENCE}

MARIA DI FRANCIA, Il purgatorio di San Patrizio, a cura di SONIA MAURA BARILLARI, Alessandria, Edizioni dell’Orso («Gli Orsatti - Testi dell'Altro Medioevo», 17), 2004, 347 pp.

1 Transmis par un manuscrit unique du XIII ${ }^{\mathrm{e}}$ siècle, l'Espurgatoire seint Patriz de Marie de France constitue le premier témoignage de la diffusion en langue d'oïl du Tractatus de Purgatorio Sancti Patricii, composé vers 1185. Sonia Maura Barillari en offre une nouvelle édition, accompagnée de traduction italienne en regard et précédée d'une solide introduction littéraire. Après avoir rappelé, sur la base des études de Jacques Le Goff, la 'naissance' du Purgatoire entre la fin du XII et le début du XIII ${ }^{\mathrm{e}}$ siècle, S. M. Barillari présente les premiers témoignages littéraires - autour de 1185 - sur le purgatoire irlandais: la Topographia Hibernica de Gérard de Cambrai, la Vita Sancti Patricii de Jocelyn de Furness, le Tractatus lui-même d'un «H. de Saltrey» par ailleurs inconnu. Elle souligne ensuite les spécificités de l'aventure ultramondaine du chevalier Owein: la visite de deux lieux ultraterrains (le purgatoire et le paradis terrestre), la précision de la topographie face à une temporalité indéterminée, le soin du cérémonial, la solitude du voyage. Le Tractatus connut un succès extraordinaire, dont témoignent une richissime tradition manuscrite et un nombre imposant de versions, réfections, traductions. La tradition du texte latin n'est cependant pas concorde: on distingue une rédaction plus brève (vraisemblablement antérieure) et une amplifiée, peut-être œuvre du même auteur. La question demeure ouverte quant à l'archétype de Marie, mais l'hypothèse d'une contamination entre version courte et version longue paraît incontestable (la table de collation proposée aux pp. 48-64 montre la dépendance de l'Espurgatoire des deux familles). Malgré une fidélité affichée au texte-source, qui jouit entre autres du prestige de sa langue de rédaction, Marie assume un rôle 'auctorial', et se fait le second auteur d'un traité associant narration et valeur exemplaire. S. M. Barillari classe ses 
interventions en: métanarratives (prologue et deux épilogues), allocutives et de commentaire, syntactiques et stylistiques, portant enfin sur le contenu. Marie maitrise non seulement le récit de son modèle, mais également les aspects théologiques qui le sous-tendent: elle souligne la 'merveille' suscitée par le purgatoire, l'interprétation des peines, la juxtaposition toujours présente corporel / spirituel. Tous ces aspects sont adaptés en vue du public laïque auquel Marie s'adresse, vraisemblablement le même des Lais, un public capable d'apprécier les traits communs avec la matière de Bretagne dont subsistent dans l'Espurgatoire quelques échos: le chevalier qui en est le seul protagoniste, l'escriture' nécessaire pour garder le souvenir de l'aventure'.

2 Les aspects philologiques ne sont pas négligés, avec une présentation soignée du manuscrit Paris BnF fr. 25407, une étude linguistique (le texte associe des traits anglonormands dans la première partie et franciens dans la seconde), et une bibliographie essentielle, raisonnée pour ce qui concerne les éditions antérieures. Le texte en ancienfrançais, vérifié sur le manuscrit, est accompagné d'un apparat très complet, qui rend compte non seulement des leçons éventuellement refusées, mais aussi des solutions adoptées par les éditeurs précédents; la version italienne - dont rien n'est dit dans l'introduction - suit de près, vers par vers, le texte de Marie, et est enrichie de notes où sont discutés certains passages, quelques aspects stylistiques et / ou difficultés de traduction. 